\title{
The R7 Subfamily of RGS Proteins Assists Tachyphylaxis and Acute Tolerance at $\mu$-Opioid Receptors
}

\author{
Javier Garzón*,', Almudena López-Fando' and Pilar Sánchez-Blázquez' \\ 'Neurofarmacología, Instituto de Neurobiología Santiago Ramón y Cajal, CSIC, Madrid, Spain
}

\begin{abstract}
Members of the R7 subfamily of regulators of G-protein signaling (RGS) proteins (RGS6, RGS7, RGS9-2, and RGSI I) are found in the mouse CNS. The expression of these proteins was effectively reduced in different neural structures by blocking their mRNA with antisense oligodeoxynucleotides (ODNs). This was achieved without noticeable changes in the binding characteristics of labeled $\beta$ endorphin to opioid receptors. Knockdown of R7 proteins enhanced the potency of antinociception promoted by morphine and [D$\mathrm{Ala}^{2}, \mathrm{~N}-\mathrm{MePhe}^{4}, \mathrm{Gly}$-o $\left.\right|^{5}$ ]-enkephalin (DAMGO) — both agonists at $\mu$-opioid receptors. The duration of morphine analgesia was greatly increased in RGS9-2 and in RGSII knockdown mice. The impairment of R7 proteins brought about different changes in the analgesic activity of selective $\delta$ agonists. Knockdown of RGSII reduced [D-Ala ${ }^{2}$ ]deltorphin II analgesic effects. Those of RGS6 and RGS9-2 proteins caused $\left[\mathrm{D}-\mathrm{Ala}^{2}\right]$ deltorphin II to produce a smoothened time-course curve-the peak effect blunted and analgesia extended during the declining phase. RGS9-2 impairment also promoted a similar pattern of change for [D-Pen ${ }^{2,5}$-enkephalin (DPDPE). RGS7deficient mice showed an increased response to both [D-Ala ${ }^{2}$ deltorphin II and DPDPE analgesic effects. A single intracerebroventricular (i.c.v.) $\mathrm{ED}_{80}$ analgesic dose of morphine gave rise to acute tolerance in control mice, but did not promote tolerance in RGS6, RGS7, RGS9-2, or RGSII knockdown animals. Thus, R7 proteins play a critical role in agonist tachyphylaxis and acute tolerance at $\mu$-opioid receptors, and show differences in their modulation of $\delta$-opioid receptors.

Neuropsychopharmacology (2003) 28, 1983-1990, advance online publication, 6 August 2003; doi: 10.1038/s.npp. 1300263
\end{abstract}

Keywords: regulator of G-protein signaling; G-proteins; antisense technology; antinociception; mouse brain

\section{INTRODUCTION}

Our knowledge of the elements involved in the cellular processing of extracellular signals now allows the identification of those responsible for opioid receptor desensitization. Studies performed with agents that alter the transduction system regulated by $\mu$-opioid receptors have reported that regulator of G-protein signaling protein (RGS) proteins modulate the timing and amplitude of opioid signals by a push-pull mechanism. The RGS2 and RGS3 proteins facilitate the activity of agonists at $\mu$-opioid receptors, whereas, the RGS7 and the CNS form of RGS9 (RGS9-2) proteins are involved in reducing the effects of agonists during their time-course-tachyphylaxis. Most importantly, RGS9-2 knockdown mice display no opioid tolerance after a single dose, or after a daily administration of morphine for 4 days (Garzón et al, 2001). Thus, RGS9-2

\footnotetext{
*Correspondence: Dr J Garzón, Neurofarmacología, Instituto Cajal, Consejo Superior de Investigaciones Científicas, Avd Doctor Arce, 37 , E-28002 Madrid, Spain, Tel: + 34 9I 585 4733, Fax: + 34 9l 585 4754, E-mail: jgarzon@cajal.csic.es

Received I 8 December 2002; revised 05 June 2003; accepted 09 June 2003

Online publication: 10 June 2003 at http://www.acnp.org/citations/ Npp06 1003020473/default.pdf
}

proteins appear to be implicated in the onset of agonist tachyphylaxis and tolerance.

The RGS proteins are GTPase-activating proteins (GAP) that contain the so-called RGS box, a conserved domain of approximately 130 amino-acid residues that binds $\mathrm{G} \alpha$-GTP subunits and accelerates GTP hydrolysis. Based on this domain, the mammalian RGS proteins have been grouped into five subfamilies, RZ, R4, R7, R12, and RA (Ross and Wilkie, 2000). The members of the R7 subfamily, RGS6, RGS7, RGS9, and RGS11 are similarly organized. The regions flanking the RGS domain all contain a DEP domain (disheveled, EGL-10, pleckstrin), the R7 homology domain (R7H), and the heterotrimeric guanine nucleotide-binding regulatory protein (G-protein) $\gamma$-subunit-like (GGL) domain (for a review, see Hollinger and Hepler, 2002). The DEP, and probably the $\mathrm{R} 7 \mathrm{H}$, domains may be involved in membrane attachment (Axelrod et al, 1998; Sondek and Siderovski, 2001). The GGL domain binds to the G $\beta 5$ protein, but not to the other G $\beta$ subunits (Snow et al, 1998; Hepler, 1999; Zhang and Simonds, 2000). Contrary to that observed for other G $\beta 1-4$ subunits, the expression of $\mathrm{G} \beta 5$ proteins is restricted to the brain (Watson et al, 1994; Zhang et al, 2000) - most are found in the plasma membrane of neural cells (Watson et al, 1996; Betty et al, 1998). The mammalian R7 proteins are also found in the CNS (Gold et al, 1997; Snow et al, 1998; Thomas et al, 1998), where they are mostly 
associated with cell membranes (Rose et al, 2000; Zhang and Simonds, 2000). In nervous tissues, the R7 proteins and G $\beta 5$ proteins are always found as dimers, indicating that this association is required for their GAP function on the corresponding G $\alpha$-GTP subunits (Snow et al, 1998; Zhang and Simonds, 2000).

RGS proteins regulate different receptors coupled to the same class of G-proteins ( $\mathrm{Ni}$ et al, 1999). However, the selectivity of RGS proteins towards certain receptors has been substantiated, although it is unknown whether this occurs by direct interaction of the RGS to the receptor, by subcellular localization, or by the influence of distinct activating properties of the receptors on the G-proteins (see eg Ross and Wilkie, 2000). The sequence identity and presence of R7 proteins in CNS suggest a homologous modulatory role on intracellular signals originating at opioid receptors. The present study addresses the participation of the different members of the R7 subfamily in agonist activity at $\mu$ - and $\delta$-opioid receptors as well as in opioid acute tolerance.

\section{MATERIALS AND METHODS}

\section{Reduction of RGS Function}

Synthetic end-capped phosphorothioate (stated as *) antisense oligodeoxynucleotides (ODN) were prepared as previously described (Garzón et al, 2000). To reduce the synthesis of RGS proteins, the following ODN sequences were used (PrimerSelect, DNASTAR Inc., Madison, WI, USA): the 18 -base ODN $5^{\prime}-A^{*} C^{\star}$ ATCCCAGAAGGCCC ${ }^{*} G^{*}$ T- $3^{\prime}$ to nucleotides $399-416$ of the murine RGS6 gene (AF061933); the 17-base ODN $5^{\prime}-\mathrm{G}^{\star} \mathrm{G}^{*}$ TCTTGTCA TAACT ${ }^{*} \mathrm{C}^{\star} \mathrm{T}-3^{\prime}$ to nucleotides 1381-1397 of the murine RGS7 gene (AF011360); the 16-base ODN $5^{\prime}-\mathrm{C}^{*} \mathrm{~T}^{\star} \mathrm{CGAAT}$ $\mathrm{CAGTTCG}^{\star} \mathrm{C}^{\star} \mathrm{T}-3^{\prime}$ to nucleotides $1044-1059$ of the murine RGS9-2 mRNA expressed in CNS (AF125046), nucleotides 973-988 of retinal RGS9-1 (AF011358) (Garzón et al, 2001); and the 18 -base ODN $5^{\prime}-\mathrm{T}^{\star} \mathrm{C}^{\star}$ TGTCTCCCTTCCGC ${ }^{\star} \mathrm{C}^{\star} \mathrm{G}-3^{\prime}$ to nucleotides $442-459$ of the murine RGS11 gene (AF061934). These sequences displayed no homology to other relevant cloned proteins (GeneBank database). Antisense ODN controls consisted of mismatched sequences in which five bases were switched without altering the remaining sequence: RGS6M, $5^{\prime}-\mathrm{A}^{*} \mathrm{G}^{\star} \mathrm{ATCGCACAAGGC}$ $\mathrm{GC}^{\star} \mathrm{G}^{\star} \mathrm{A}-\mathbf{3}^{\prime}$; RGS7M, $5^{\prime}-\mathrm{G}^{\star} \mathrm{G}^{\star} \mathrm{ACTTCTCAATACT}^{\star} \mathrm{G}^{\star} \mathrm{T}-3^{\prime}$; RGS9-2M, $5^{\prime}-C^{\star} T^{\star}$ GCAATGAGTTGC ${ }^{\star} \mathrm{T}^{\star} \mathrm{C}-3^{\prime}$, and RGS11M, $5^{\prime}-\mathrm{T}^{\star} \mathrm{C}^{\star} \mathrm{AGTCTCCGATCCCG}{ }^{*} \mathrm{C}^{\star} \mathrm{G}-3^{\prime}$. A random ODN (ODN-RD) previously characterized as not altering the analgesic activity of the opioids included in this study (Sánchez-Blázquez et al, 1995) was also used as a control.

ODN solutions were made up in saline immediately prior to use. Each ODN treatment was performed on a different group of mice according to the following 5-day schedule: on days 1 and 2 with $1 \mathrm{nmol}$, on days 3 and 4 with $2 \mathrm{nmol}$, and on day 5 with $3 \mathrm{nmol}$ (Sánchez-Blázquez et al, 1995; Garzón et al, 2000). Functional studies usually started on day 6 . The possible alterations to animal activity promoted by ODN treatments were recorded with a Digiscan animal activity monitor system (activity cage) (Omnitech electronics, Columbus, OH, USA). Groups of four mice that had received an ODN following the above-described schedule were monitored for horizontal and vertical activity for periods of $10 \mathrm{~min}$. Only ODNs that produced no significant changes in these behavioral parameters were selected for this study (ANOVA, Student-Newman-Keuls test, $P<0.05$ ).

To monitor any possible injury to tissue structure caused by intracerebroventricular (i.c.v.)-delivery of the ODNs, Nissl staining was routinely performed on brain coronal slices from mice receiving each ODN treatment. These slices included some of the periventricular regions responsible for the antinociceptive effects of opioids injected via the i.c.v. route (Yaksh et al, 1976; Rossi et al, 1994). The histological procedure is described elsewhere (Garzón et al, 2000). The ODNs produced no alterations to the normal structure of periaqueductal gray matter (PAG) or any other periventricular region (not shown).

\section{Detection of RGS in Mouse Brain: Electrophoresis and Immunoblotting}

At the end of ODN treatment, the mice were killed by decapitation. The animals' cerebral cortices, hypothalamus, and PAG were then collected. For each determination, the structures from four mice were pooled and SDS-solubilized P2 membranes were subsequently resolved by SDS/ polyacrylamide gel electrophoresis (PAGE) in $8 \mathrm{~cm} \times 11 \mathrm{~cm} \times 1.5 \mathrm{~cm}$ gel slabs $(10-20 \%$ total acrylamide concentration $/ 2.6 \%$ bisacrylamide cross-linker concentration). For RGS immunodetection, $60 \mu \mathrm{g}$ protein/lane was used for every neural structure. The separated proteins were then transferred onto $0.2 \mu \mathrm{m}$ polyvinylidene difluoride membranes (BioRad). Polyclonal anti-RGS7 (SC8139), anti-RGS9 (SC8143), and anti-RGS11 (SC9724) 1:500 (Santa Cruz Biotechnology, Inc., Santa Cruz, CA, USA) were diluted in Tris-buffered saline-0.05\% Tween 20 (TTBS) and incubated with the transfer membranes at $6^{\circ} \mathrm{C}$ for $24 \mathrm{~h}$. The SC antibodies (raised in goats) were detected with donkey anti-goat IgG horseradish peroxidase conjugate antiserum (Santa Cruz Biotechnology, SC2020). Secondary antisera were diluted $1: 2000$ in TTBS, incubated for $3 \mathrm{~h}$ and visualized with the DAB substrate solution. Immunoblots were analyzed by densitometry using an instrument with reflectance capabilities (GS-700 Imaging Densitometer, BioRad) and Molecular Analyst Software (v 1.5) (BioRad).

\section{Animals and Evaluation of Antinociception}

Male albino mice CD-1 (Charles River) weighing 22-25g were housed and used strictly in accordance with the guidelines of the European Community for the Care and Use of Laboratory Animals (Council Directive 86/609/EEC). Animals were lightly anaesthetized with ether and all substances injected into the right lateral ventricle in $4 \mu \mathrm{l}$ volumes as previously described (Sánchez-Blázquez et al, 1995). The response of the animals to nociceptive stimuli was determined by the warm water $\left(52^{\circ} \mathrm{C}\right)$ tail-flick test. Antinociception was expressed as a percentage of the maximum possible effect, MPE $=100 \times$ (test latency-basebaseline latency)/(cut-off time (10 s)-baseline latency). The observed baseline latencies for the different groups studied were in seconds (mean \pm SEM, $n=20$ ): naïve $1.77 \pm 0.06$, ODN vehicle $1.68 \pm 0.06$, ODN-RD $1.82 \pm 0.09$, ODNRGS6M $1.69 \pm 0.07$, ODN-RGS6 $1.78 \pm 0.05$, ODN-RGS7M 
$1.80 \pm 0.08, \quad$ ODN-RGS7 $1.76 \pm 0.07, \quad$ ODN-RGS9-2M $1.69 \pm 0.07, \quad$ ODN-RGS9-2 $1.72 \pm 0.06, \quad$ ODN-RGS11M $1.79 \pm 0.07$, ODN-RGS11 $1.83 \pm 0.05$. For the different assays of the study, a fixed dose of the opioid agonists was given and antinociception was assessed in time-course studies at various intervals after injection. The peak effect was included in the analysis (30 min after morphine sulfate (Merck, Darmstadt, Germany), human $\beta$-endorphin-(1-31) (Peninsula Laboratories, \#8616, San Carlos, CA, USA), 15 min after $\left[\mathrm{D}-\mathrm{Ala}^{2}, \mathrm{~N}-\mathrm{MePhe}^{4}, \mathrm{Gly}^{-\mathrm{ol}^{5}}\right.$ ]-enkephalin (DAMGO) (Bachem, H-2535), [D-Pen $\left.{ }^{2,5}\right]$-enkephalin (DPDPE) (Bachem, H-2905), and [D-Ala $\left.{ }^{2}\right]$ deltorphin II (Peninsula Labs., \#8257)). Statistical analysis of the results was performed by analysis of variance (ANOVA) followed by the Student-Newman-Keuls test (SigmaStat, SPSS Science Software, Erkrath, Germany). The level of significance was set at $P<0.05$.

\section{Production and Evaluation of Acute Tolerance to Morphine}

A single i.c.v. injection of $10 \mathrm{nmol}$ morphine (priming dose: PD) was used to produce acute tolerance (Garzón and Sánchez-Blázquez, 2001). Controls were given saline instead. A second i.c.v. dose of $10 \mathrm{nmol}$ morphine (test dose: TD) was given at least $24 \mathrm{~h}$ later when the pretreatment (PD) had no effect on baseline latencies. Analgesia was determined $30 \mathrm{~min}$ later by the tail-flick test. Acute tolerance was determined by the decrease of antinociceptive potency.

\section{Preparation of PAG Mouse Membranes and Binding Studies}

Experimental tissue was obtained and prepared as described (Garzón et al, 2001). Briefly, albino, male, CD/1 mice weighing 22-27 $\mathrm{g}$ who had received i.c.v. injections of the ODNs were killed by cervical dislocation. PAG (about $1 \mathrm{~mm}$ around the aqueduct) were collected to obtain the pellet $\left(\mathrm{P}_{2}\right)$ in Tris buffer supplemented with a mixture of protease inhibitors $(0.2 \mathrm{mM}$ phenylmethylsulfonyl fluoride, $2 \mu \mathrm{g} / \mathrm{ml}$ leupeptin, and $0.5 \mu \mathrm{g} / \mathrm{ml}$ aprotinin). (3-Iodotyrosyl ${ }^{27}$ )- $\beta$-Endorphin-(1-31) (human) (IM162, $2000 \mathrm{Ci} / \mathrm{mmol}$ ) was obtained from Amersham Biosciences (Buckinghamshire, UK). Binding assays were carried out as previously described (Garzón et al, 1998, 2001). For saturation assays, ${ }^{125} \mathrm{I}_{-} \mathrm{Tyr}^{27}$ human $\beta$-endorphin was used at concentrations ranging from $0.3 \mathrm{pM}$ to $3 \mathrm{nM}$. The membrane suspension reached a final concentration of about $0.2 \mathrm{mg} / \mathrm{ml}$. The incubation volume was made up to $2 \mathrm{ml}$ with $50 \mathrm{mM}$ (final concentration) Tris- $\mathrm{HCl}$ buffer, $\mathrm{pH}$ 7.5 , and supplemented with $0.2 \%$ BSA, $0.01 \%$ bacitracin.

\section{RESULTS}

After resolving mouse cerebral cortex, hypothalamus, and PAG by SDS-PAGE, the antibodies directed to R7 proteins recognized bands of about $55 \mathrm{kDa}$ for RGS7 (Kim et al, 1999; Posner et al, 1999), $75 \mathrm{kDa}$ for RGS9-2 (Granneman et al, 1998; Rahman et al, 1999; Garzón et al, 2001), and $50 \mathrm{kDa}$ for RGS11 (Snow et al, 1998). The vehicle, ODN-RD, or ODN-RGS\#M administration brought about no significant variations on the immunoreactivity associated to R7 proteins observed in saline-treated mice. The values mean \pm SEM percent of control (naïve) of three independent determinations were for RGS7, RGS9-2, and RGS11 PAG signals: ODN vehicle 95.2 $\pm 7.6,104.0 \pm 9.3$, $93.8 \pm 9.3 ;$ ODN-RD $108.2 \pm 10.4,89.5 \pm 8.8,102.8 \pm 8.0$; ODN-RGS6M 112.4 $\pm 14.2,98.0 \pm 10.5,101.4 \pm 7.2$; ODNRGS7M 88.4 \pm 9.2, $104.8 \pm 9.7,91.7 \pm 6.2$; ODN-RGS9-2M $93.0 \pm 7.0,95.5 \pm 8.1,105 \pm 8.2 ;$ ODN-RGS11M 94.0 \pm 6.2 , $108.1 \pm 9.2,102.7 \pm 7.4$. In mice treated with the ODNs to R7 proteins, a significant decrease in the immunolabeling of the antibodies was seen. Figure 1 shows the data corresponding to ODNs directed to RGS7, RGS9-2, and RGS11. The effect of the active ODNs brought about reductions in immunoreactivity that ranged between 40 and $60 \%$ of that observed for control neural structures. The knockdown of either R7 protein did not change the expression of others implicated in opioid cellular signaling, for example, G $\beta 1 / 2$ subunits, Gi2 $\alpha$ subunits, or the $\mu$-opioid receptor (not shown). Results corresponding to ODN-RGS9-2 have already been reported (Garzón et al, 2001). No antibody to RGS6 protein is currently available.

As the supraspinal analgesic effect of agonists at $\delta$-opioid receptors in CD-1 mice is moderate compared to that of $\mu$ binding agonists (see eg Sánchez-Blázquez and Garzón, 1993; Sánchez-Blázquez et al, 1993), the doses of the opioids were selected to produce effects of about $40 \%$ MPE in control mice. No significant differences were observed in the analgesic response to the opioids of saline or mismatched ODN-treated mice. The saline and mismatched ODN-RGS\# curves always coincided. Therefore, only the data for saline are provided for the RGS6 study (Figure 2). In animals treated with ODNs to RGS proteins of the R7 subfamily, the potency of morphine increased over the effective time-course, the ODN-RGS11 being weaker during the initial period following i.c.v.-injection of the opioid. For the ODNs to RGS9-2 and RGS11, morphine also became efficacious for longer postopioid intervals. The knockdown of R7 proteins also brought about enhancement of DAMGO-evoked antinociception similar to what was seen for morphine (Figures 2 and 3 ). The analgesia of the selective agonist at $\delta$-opioid receptors, DPDPE, was not altered by experimental reduction of RGS6 or RGS11 proteins. RGS9-2 knockdown reduced the initial effects of the $\delta$ agonists around the peak effect, $15 \mathrm{~min}$, but their potency increased during the phase in which the analgesia declined (Figure 3). The impairment of RGS6 proteins produced this effect on [D-Ala ${ }^{2}$ deltorphin IIevoked antinociception (Figure 2). RGS11 knockdown reduced the efficacy of only $\left[\mathrm{D}-\mathrm{Ala}^{2}\right]$ deltorphin II. Depletion of RGS7 proteins increased analgesia of [D-Ala ${ }^{2}$ ] deltorphin II and DPDPE over the time-course of their effects (Figure 2).

The possible effect of knockdown of R7 proteins on opioid receptors was analyzed in membranes from mouse PAG. The binding profile of ${ }^{125} \mathrm{I}-\mathrm{Tyr}^{27}$ human $\beta$-endorphin to this receptor underwent no change because of the treatment with ODNs directed to RGS6, RGS7, RGS9-2, or RGS11 proteins. The affinity of the labeled opioid was about $0.34-0.36 \mathrm{nM}$ and the binding capacity was approximately $47-55 \mathrm{fmol} / \mathrm{mg}$ of membrane protein (Table 1 ). 
PAG Hypoth Cortex
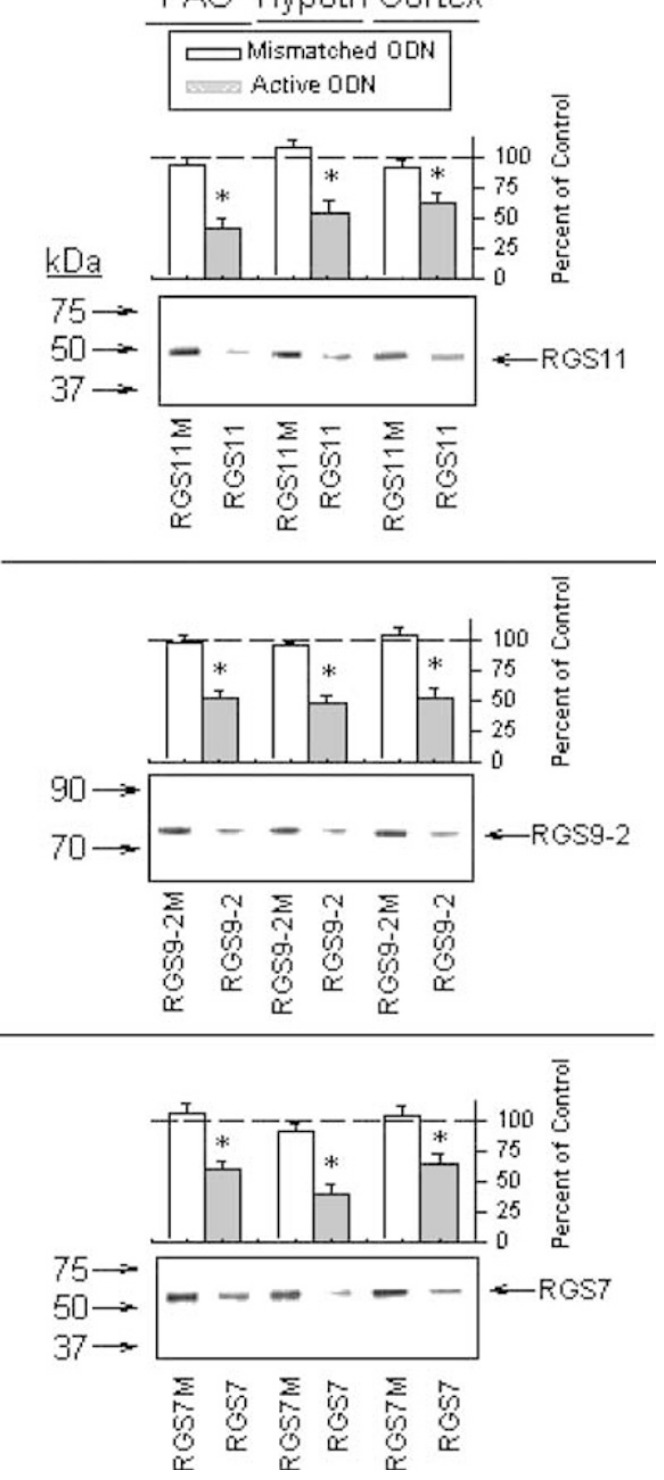

Figure I Detection of R7 proteins in mouse brain: efficacy and selectivity of the ODN treatments. Animals received either the mismatched ODN or the active antisense ODN into the right lateral ventricle over a 5day schedule. On day 6, the mice were killed by decapitation and neural structures were collected. Antibodies directed to RGS7, RGS9, and RGSI I proteins were used. SDS-solubilized PAG, hypothalamus, and cerebral cortex were resolved by SDS-PAGE ( I 0-20\% acrylamide/2.6\% bisacrylamide) and Western blotted. Immunodetection was carried out as described in Materials and methods. The immunosignals were analyzed by densitometry (GS-700 Imaging Densitometer, BioRad) and employing Molecular Analyst Software ( $v$ I.5). Each bar is the mean \pm SEM percentage change from the saline-treated control (dashed line) of three to four independent determinations. *Significantly different from the salinetreated group, ANOVA-Student-Newman-Keuls test; $P<0.05$.

It has been reported that knockdown of RGS9-2 proteins produces a potent enhancement of $\beta$-endorphin antinociceptive activity (Garzón et al, 2001). Also, by increasing the availability of biologically active $\mathrm{G} \alpha$ subunits with i.c.v.-injection of 12 pmol biologically active myristoylated $\mathrm{myr}^{+}-\mathrm{Gi} 2 \alpha$ subunits, the potency of $\beta$-endorphin-induced analgesia increases (Garzón and Sánchez-Blázquez, 2001). In the present work, the injection of $\mathrm{G} \alpha$ subunits did not further boost $\beta$-endorphin activity when the animals
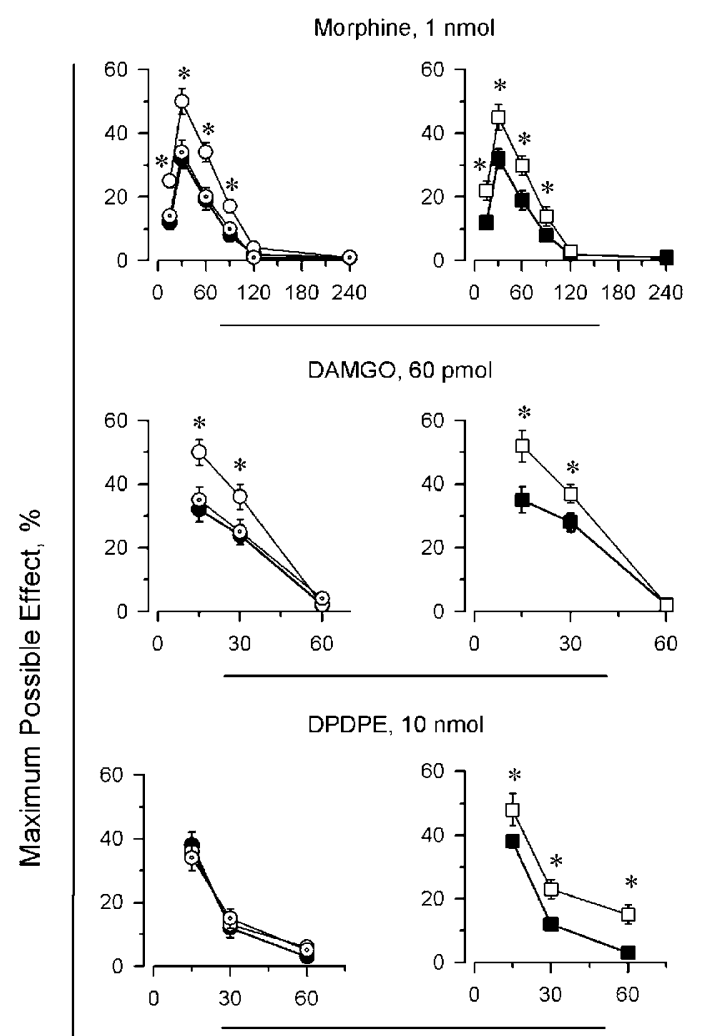

$\left[\mathrm{D}-\mathrm{Ala}^{2}\right]$ deltorphin II, $10 \mathrm{nmol}$
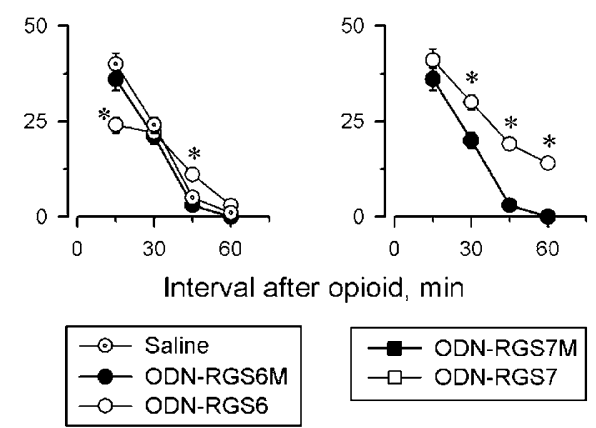

- ODN-RGS7M

$\rightarrow-$ ODN-RGS7

Figure 2 Effect of ODNs to RGS6 and RGS7 proteins on the timecourse of the analgesia evoked by $\mu$ - and $\delta$-opioid receptor acting agonists. Animals received the ODN treatment over a 5-day schedule. On day 6, the animals were i.c.v.-injected with the opioids and analgesia was determined by the warm water $52^{\circ} \mathrm{C}$ tail-flick test at various intervals postinjection. Values are means \pm SEM from groups of 10-20 mice. *Significantly different from the group that had received the mismatched ODN.

underwent RGS9-2 knockdown (Figure 4). This result suggests that a common mechanism (an increased pool of receptor-regulated G-proteins) mediates the influence of RGS9-2 knockdown or $\mathrm{myr}^{+}$-Gi2 $\alpha$ subunits on $\beta$-endorphin analgesia.

The development of tolerance to an acute dose of morphine was investigated in mice with reduced levels of the R7 proteins. Different groups of mice received the active ODNs. Since neither the mismatched ODNs to R7 proteins nor the ODN-RD produced changes in morphine activity compared to naïve mice, the results obtained with the ODN$\mathrm{RD}$ are presented as those of the control. After completing 5 days of oligo treatment, half of the animals of every group received a $\mathrm{PD}$ of $10 \mathrm{nmol}$ morphine. The remaining animals 


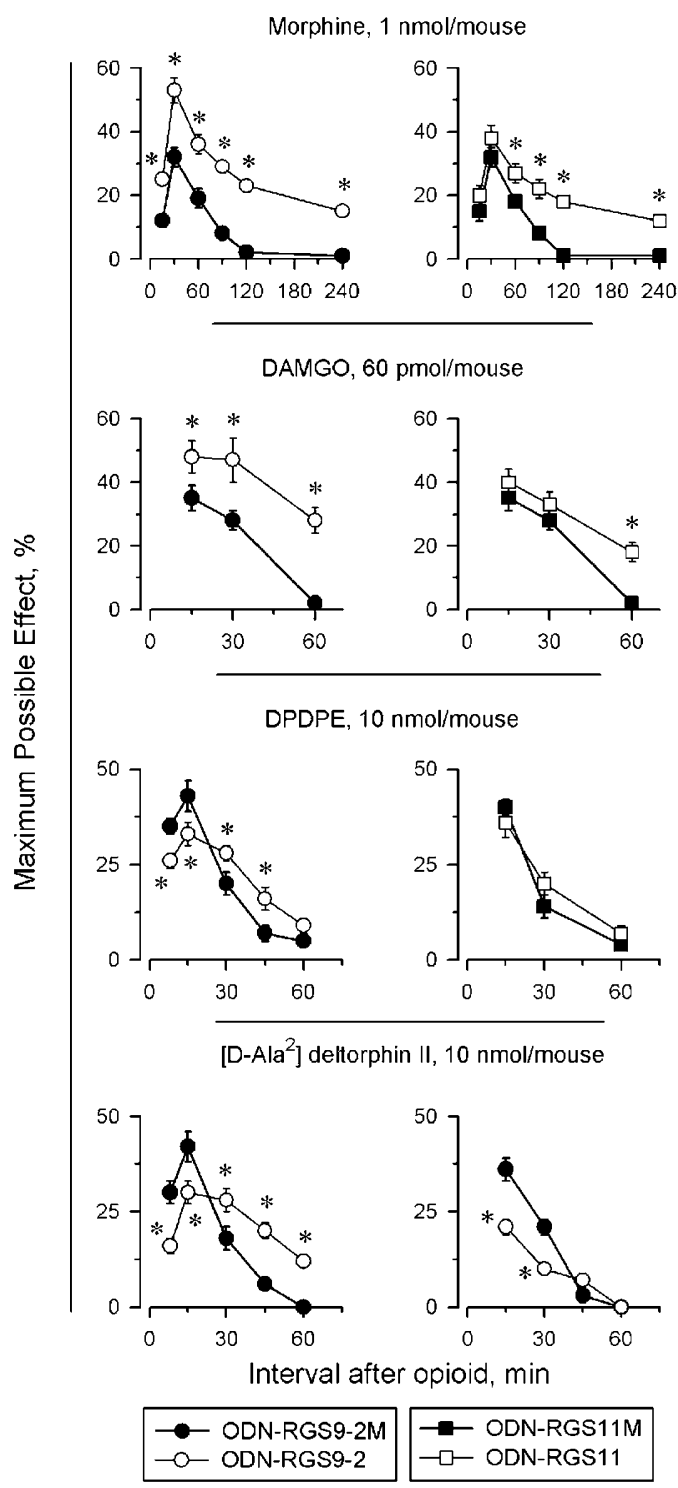

Figure 3 Knockdown of RGS9-2 and RGSII proteins on the timecourse of the analgesia evoked by $\mu$ - and $\delta$-opioid receptor acting agonists. Details as in the legend to Figure 2.

Table I Specific Binding Displayed by Human ${ }^{125}{ }_{-T y r^{27}}$ Human $\beta$ Endorphin-( $|-3|$ ) to Opioid Receptors in Mouse PAG Membranes from RGS6, RGS7, RGS9-2, and RGSI I Knockdown Mice

\begin{tabular}{|c|c|c|}
\hline Treatment & $K_{\mathrm{d}}(\mathrm{nM})$ & $\begin{array}{l}B_{\max }\left(\mathrm{fmol}{ }^{125} \mathrm{I}-\mathrm{Tyr}^{27}\right. \\
\text { human } \beta \text {-endorphin } \\
\text { per } \mathrm{mg} \text { of protein })\end{array}$ \\
\hline ODN-RD & $0.36(0.43-0.30)$ & $47(56-39)$ \\
\hline ODN-RGS6 & $0.34(0.40-0.28)$ & $52(63-42)$ \\
\hline ODN-RGS7 & $0.36(0.4|-0.3|)$ & $49(59-40)$ \\
\hline ODN-RGS9-2 & $0.38(0.43-0.33)$ & $54(64-45)$ \\
\hline ODN-RGSII & $0.39(0.45-0.34)$ & $55(68-44)$ \\
\hline
\end{tabular}

The animals were killed $24 \mathrm{~h}$ after finishing the ODN treatment and PAG membranes were prepared. For each ODN-RGS treatment, increasing concentrations of ${ }^{125} 1-$ Tyr $^{27}$ human $\beta$-endorphin were incubated with $0.2 \mathrm{mg} / \mathrm{ml}$ final protein concentration at $25^{\circ} \mathrm{C}$ for $90 \mathrm{~min}$ (Garzón et al, 1998). $K_{d}$ values, $B_{\max }$, and $95 \%$ confidence limits were derived using the Ligand weighted nonlinear least squares regression program (Munson and Rodbard, 1980).

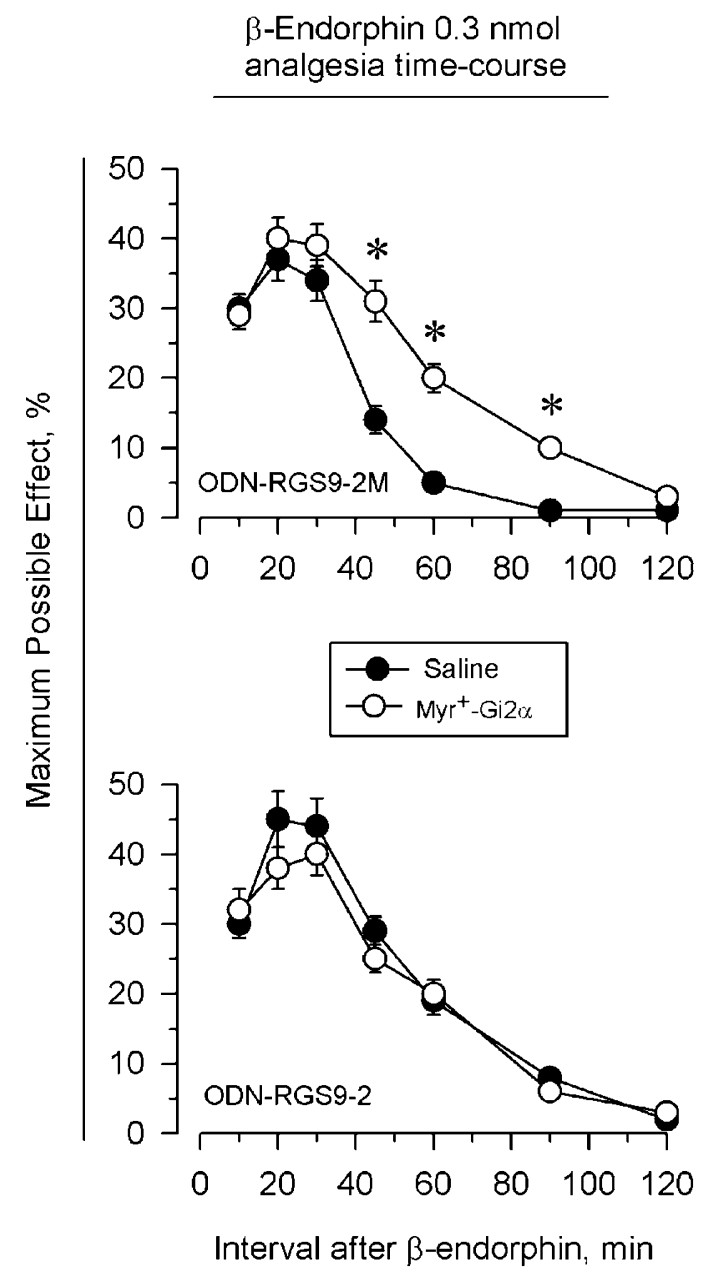

Figure 4 Effect of RGS9-2 knockdown and myr ${ }^{+}-\mathrm{Gi} 2 \alpha$ subunits on the time-course of $\beta$-endorphin-evoked analgesia. Animals with reduced levels of RGS9-2 proteins (through ODN treatment) and their controls (given ODN-RGS9-2M) received 12 pmol myr ${ }^{+}$-Gi2 $\alpha$ subunits or saline i.c.v.injected $2 \mathrm{~h}$ before $0.3 \mathrm{nmol} \beta$-endorphin. Analgesia was determined at various intervals by the warm water $52^{\circ} \mathrm{C}$ tail-flick test. Values are mean \pm SEM from groups of 10-20 mice. *Significantly different from the ODN-RGS9-2M-treated group that had received saline instead of the myr ${ }^{+}-\mathrm{Gi} 2 \alpha$ subunits.

were given saline instead. To detect the appearance of opioid acute tolerance, a TD of $10 \mathrm{nmol}$ morphine was i.c.v.-injected $24 \mathrm{~h}$ later into all mice. Antinociception was then evaluated $30 \mathrm{~min}$ later by the tail-flick test. The control group that received the PD and the TD of morphine showed a marked impairment of the opioid analgesic effect (Figure 5). The knockdown of either of the R7 proteins resulted in morphine displaying no reduced activity.

It should be noted that mice treated with the active ODNRGS\#, who received saline instead of the morphine PD, showed no potentiation of morphine TD when compared to the ODN-RD control group (Figure 5). This has already been observed for ODN-RGS9-2 and $10 \mathrm{nmol}$ morphine analgesia at the peak effect $(30 \mathrm{~min})$. At this interval, the higher the dose of morphine the lower the enhancement of opioid effect promoted by RGS9-2 knockdown. However, at later time-course intervals, the analgesic activity of the opioid is effectively increased (Garzón et al, 2001). 


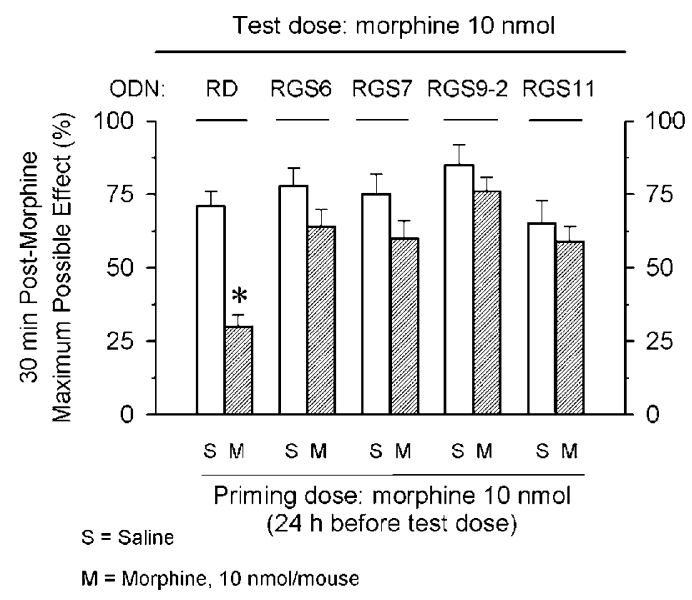

Figure 5 Role of R7 proteins on acute tolerance to a single dose of morphine. Saline or a PD of I0-nmol morphine was i.c.v.-injected into the mice who had received the ODNs to R7 proteins or the control ODNRD. All groups received, $24 \mathrm{~h}$ later, an i.c.v. test injection of $10 \mathrm{nmol}$ morphine, and analgesia was evaluated after 30 min. Values are mean \pm SEM from groups of 10-20 mice. *Significantly different from the group injected with saline before the second dose of the opioid.

\section{DISCUSSION}

The PAG plays a major role in mediating the supraspinal analgesic effects of opioids when given by the i.c.v. route (Yaksh et al, 1976; Jensen and Yaksh, 1986). Therefore, the presence of the R7 proteins in PAG validates the ODN approach used in this study. The knockdown of the R7 proteins in mouse CNS produced no apparent changes in the properties of opioid receptors. Thus, the different modulatory profiles exhibited by R7 proteins on $\mu$ - and $\delta$ mediated effects should be analyzed in the framework of their particular CNS distribution, receptor preference, and exerted GAP activity on the distinct classes of opioid receptor-activated $\mathrm{G} \alpha$ subunits. The majority of the RGS proteins are GAPs for Gi/o $\alpha$ and Gq $\alpha$, but not for Gs $\alpha$ subunits, which are deactivated by RGS-PX1 (Zheng et al, 2001). In contrast, conflicting results have been reported for the selectivity of R7 proteins towards classes of activated $\mathrm{G} \alpha$ subunits. The complex RGS7/ $\beta 5$ has GAP activity towards Go $\alpha$, but not on Gi1 $\alpha$ or Gi2 $\alpha$ (Posner et al, 1999; Rose et al, 2000). The GAP activities of the RGS6/ $\beta 5$ and RGS11/ $/ 35$ complexes also appear specific for Go $\alpha$-GTP (Snow et al, 1998; Posner et al, 1999). However, R7 proteins have been shown to bind to activated $\mathrm{Go} \alpha$, Gi $3 \alpha$, and Gz $\alpha$ subunits in rat and mouse brain membrane fractions (Saitoh et al, 1999: Rose et al, 2000; Sánchez-Blázquez et al, 2003). It is therefore possible that to show GAP activity on G $\alpha$-GTP subunits - distinct from Go $\alpha-\mathrm{R} 7 / \beta 5$ complexes require the assistance of as yet unidentified auxiliary proteins. Alternatively, because of their modest GAP activity, R7 proteins could act as scavengers for $\mathrm{Gi} / \mathrm{z} \alpha$ subunits. $\mathrm{R} 7 / \beta 5$ complexes might sequester G $\alpha$-GDP subunits previously deactivated by other RGS proteins by acting as $G \beta \gamma$ dimers. These R7/ $\beta 5 / \mathrm{G} \alpha$-GDP heterotrimers could also be under regulation of receptors (Sondek and Siderovski, 2001).

Thus, selectivity towards activated $\mathrm{G} \alpha$ subunits and GAP efficiency will certainly influence the kind of regulation exerted by R7 proteins on opioid-activated signaling pathways. In the production of supraspinal analgesia, Gz,
$\mathrm{Gi} 2$, and to a lesser extent $\mathrm{Go}$ and $\mathrm{Gq}$, proteins are activated by morphine and DAMGO. The Gi/o1/o2/q/11 proteins are mostly activated by agonists at $\delta$-opioid receptors (SánchezBlázquez et al, 1995; Sánchez-Blázquez and Garzón, 1998; Standifer et al, 1996; Garzón et al, 2000). Knockdown of R7 proteins notably increased the potency and duration of the antinociceptive activity of morphine and DAMGO agonists at $\mu$-opioid receptors. In RGS9-2 and RGS11 knockdown mice, this enhancement was particularly observable when activity started to decline in control mice. The effects on the experimental impairment of R7 proteins were dissimilar on the analgesic activity of DPDPE agonist at pharmacologically defined $\delta-1$ receptors, and [D-Ala $\left.{ }^{2}\right]$ deltorphin II agonist at $\delta-2$ receptors. The potency of DPDPE did no change after depletion of RGS6 and RGS11 proteins. The effects of DPDPE and [D-Ala ${ }^{2}$ deltorphin II were increased in RGS7 and RGS9-2 knockdown mice. However, depletion of RGS9-2 proteins also diminished their potency at the early intervals when the agonists' effects peaked. A pattern similar to that produced by RGS9-2 knockdown on $\left[\mathrm{D}-\mathrm{Ala}^{2}\right]$ deltorphin II-evoked antinociception was brought about by impairment of RGS6 proteins, whereas depletion of RGS11 reduced the activity of the $\delta$-2 agonist. These results indicate that GAP activity of RGS9-2, RGS6, and RGS11 facilitates the early effects of $\delta$ agonists by increasing the availability of $\delta$-receptor-regulated Go-proteins. They also indicate a scavenger role of RGS6, RGS7, and RGS9-2 towards the classes of $\mathrm{G} \alpha$ subunits that are activated by these $\delta$ agonists in the production of the later effects. The differences displayed by R7 proteins on the regulation of DPDPE and $\left[\mathrm{D}-\mathrm{Ala}^{2}\right]$ deltorphin II analgesia could reflect differences in the classes of G-proteins that are activated by these agonists. Go2 proteins mediate the supraspinal antinociception produced by both agonists. However, Go1 proteins are selectively linked to DPDPE-, and Gq proteins are related to $\left[\mathrm{D}-\mathrm{Ala}^{2}\right]$ deltorphin II-evoked antinociception (Sánchez-Blázquez and Garzón, 1998). Unfortunately, there are no data in the literature comparatively describing the GAP activity of R7 proteins on Gol $\alpha$ and Go2 $\alpha$ subunits.

The binding of activated $\mathrm{Gi} / \mathrm{z} \alpha$ subunits to low GAP efficiency R7 proteins would delay or even prevent G $\alpha$-GDP from binding to $\mathrm{G} \beta \gamma$ dimers and increase the rate of desensitization of $\mu$-opioid receptors. RGS proteins members of the $\mathrm{R} 4$ and $\mathrm{Rz}$ subfamilies, which exhibit high catalytic efficiency towards activated $\mathrm{G} \alpha$ subunits, facilitate the activity of agonists at these receptors (Garzón et al, 2001). Accordingly, R7 knockdown increases the probability of high GAP activity RGS to act on opioid agonist-activated $\mathrm{G} \alpha$ subunits. This action permits the rapid formation of the $\mathrm{G} \alpha$-GDP pool that binds to $\mathrm{G} \beta \gamma$ dimers to reform receptor regulated G-proteins. No agonist tachyphylaxis develops. The negative regulation of G-protein signaling of R7 proteins could also account for the long duration of opioid acute tolerance that persists for several days until the initial response to the opioids is recovered (Huidobro-Toro and Way, 1978; Garzón et al, 2001). The period that the agonists at $\mu$-opioid receptors require to recover full activity coincides with the estimated turnover rate of $\mathrm{Gi} / \mathrm{o} \alpha$ subunits (Sánchez-Blázquez and Garzón, 1993; Sánchez-Blázquez et al, 1993). Both R7 knockdown and the administration of biologically active Gi2 $\alpha$ subunits prevent tachyphylaxis 
and acute tolerance at $\mu$-opioid receptors (this paper; Garzón and Sánchez-Blázquez, 2001; Garzón et al, 2001). The experimental increase of available Gi $\alpha$ subunits and RGS9-2 knockdown enhanced the potency and duration of opioid analgesic effects in a comparable manner, and were not additive. These and previous results indicate that tachyphylaxis develops during the course of the agonist effect as a consequence of the progressive reduction of opioid receptor-regulated G-proteins (Garzón et al, 1999, 2001; Garzón and Sánchez-Blázquez, 2001; Sánchez-Blázquez et al, 2003).

It has recently been suggested that $\mathrm{R} 7 / \beta 5$ complexes might function as $G \beta \gamma$ dimers in receptor-coupled activation of G-proteins, conforming with G $\alpha$-GDP subunits receptor-regulated heterotrimers (Sondek and Siderovski, 2001). Agonist-induced activation of these receptors would provide $\mathrm{G} \alpha$-GTP subunits plus freed R7/ $\beta 5$ complexes that could sequester $\mathrm{G} \alpha$ subunits being activated by other receptors (Sierra et al, 2000). $\mu$-opioid receptors form heterodimers or oligomers with other receptors, $\delta$ receptor included (see review Levac et al, 2002). Interestingly, there is general agreement on the role of $\delta$-opioid receptors in the development of $\mu$-mediated tolerance and physical dependence, particularly with respect to morphine. The pharmacological blockade or ODN-induced downregulation of $\delta$ receptors diminishes the development of tolerance to and dependence on morphine (Abdelhamid et al, 1991; Miyamoto et al, 1993; Kest et al, 1996; Sánchez-Blázquez et al, $1997)$. Knockout of the $\delta$-opioid receptor gene leads to no analgesic tolerance to morphine in these mice (Zhu et al, 1999). Neither do mice lacking the preproenkephalin gene (that generates the endogenous ligands to the $\delta$-opioid receptors) display tolerance to morphine (Nitsche et al, 2002). If R7 proteins show $\delta$ receptor-selective interaction, then activation of these opioid receptors would provide specificity in the action of these RGS proteins on $\mu$ receptor-mediated effects. R7/ $\beta 5$ complexes could provide G $\alpha$-GDP subunits for $\delta$ receptor regulation, mostly $\mathrm{G} \alpha \mathrm{o}$, which are regulated by this receptor to produce analgesia. The action of the enkephalins at $\delta$ receptors in releasing the R7/ $\beta 5$ complexes could increase the sequestering of Gai/z-GTP subunits and thus promote the development of agonist tachyphylaxis and acute tolerance at $\mu$ receptors.

In summary, the RGS members of the R7 subfamily are implicated in the signaling mechanisms that modulate the potency and duration of opioid effects at $\mu$ - and $\delta$-opioid receptors. The integrity of these proteins restrains the amplitude and duration of opioid analgesia at $\mu$ receptors, whereas different modulatory roles are observed for these proteins at $\delta$-opioid receptors. Tachyphylaxis and acute tolerance at $\mu$-opioid receptors appear to be a cell membrane-limited process facilitated by $\mathrm{R} 7 / \beta 5$ heterodimers, which might involve the sequestration of agonistsegregated $\mathrm{G} \alpha$ subunits over the time-course of the effect. These results, as well as those of previous reports (Garzón et al, 2001, 2002; Sánchez-Blázquez et al, 2003), indicate that agonist tachyphylaxis at $\mu$-opioid receptors or acute tolerance can be accomplished by processes not directed related to agonist-evoked receptor uncoupling from Gproteins, that is, phosphorylation and subsequent internalization.

\section{ACKNOWLEDGEMENTS}

This work was supported by funding from FIS 01/1169 and DGICYT PB98-0649. Almudena López-Fando is a predoctoral fellow from FPI (MEC).

\section{REFERENCES}

Abdelhamid EE, Sultana M, Portoghese PS, Takemori AE (1991). Selective blockage of $\delta$ opioid receptors prevents the development of morphine tolerance and dependence in mice. $J$ Pharmacol Exp Ther 258: 299-303.

Axelrod JD, Miller JR, Shulman JM, Moon RT, Rerrimon N (1998). Differential recruitment of Dishevelled provides signaling specificity in the planar cell polarity and Wingless signaling pathways. Genes Dev 12: 2610-2622.

Betty M, Harnish SW, Rhodes KJ, Cockett MI (1998). Distribution of heterotrimeric G-protein $\beta$ and $\gamma$ subunits in the rat brain. Neuroscience 85: 475-486.

Garzón J, Castro M, Sánchez-Blázquez P (1998). Influence of Gz and $\mathrm{Gi} 2$ transducer proteins in the affinity of opioid agonists to $\mu$ receptors. Eur J Neurosci 10: 2557-2564.

Garzón J, DeAntonio I, Sánchez-Blázquez P (2000). In vivo modulation of G-proteins and opioid receptor function by antisense oligodeoxynucleotides. Meth Enzymol 314: 3-20.

Garzón J, Rodríguez-Díaz M, DeAntonio I, DeFelipe J, Rodriguez JR, Sánchez-Blázquez $P$ (1999). $\mathrm{Myr}^{+}-\mathrm{G}_{\mathrm{i} 2} \alpha$ and $\mathrm{G}_{\mathrm{o}} \alpha$ subunits restore the efficacy of opioids, clonidine and neurotensin giving rise to antinociception in G-protein knock-down mice. Neuropharmacology 38: 1861-1873.

Garzón J, Rodríguez-Díaz M, López-Fando A, García-España A, Sánchez-Blázquez P (2002). Glycosylated phosducin-like protein long regulates opioid receptor function in mouse brain. Neuropharmacology 42: 813-828.

Garzón J, Rodríguez-Díaz M, López-Fando A, Sánchez-Blázquez P (2001). RGS9 proteins facilitate acute tolerance to mu-opioid effects. Eur J Neurosci 13: 801-811.

Garzón J, Sánchez-Blázquez P (2001). Administration of $\mathrm{myr}^{+}-\mathrm{G}_{\mathrm{i} 2} \alpha$ subunits prevents acute tolerance (tachyphylaxis) to mu-opioid effects in mice. Neuropharmacology 40: 560-569.

Gold SJ, Ni YG, Dohlmam HG, Nestler EJ (1997). Regulators of Gprotein signaling (RGS) proteins; region-specific expression of nine subtypes in rat brain. J Neurosci 17: 8024-8037.

Granneman JG, Zhai Y, Zhu Z, Bannon MJ, Burchett SA, Schmidt CJ et al (1998). Molecular characterization of human and rat RGS 9L, a novel splice variant enriched in dopamine target regions, and chromosomal localization of the RGS 9 gene. $\mathrm{Mol}$ Pharmacol 54: 687-694.

Hepler JR (1999). Emerging roles for RGS proteins in cell signalling. Trends Pharmacol Sci 20: 376-382.

Hollinger S, Hepler JR (2002). Cellular regulation of RGS proteins: modulators and integrators of $\mathrm{G}$ protein signaling. Pharmacol Rev 54: 527-559.

Huidobro-Toro JP, Way EL (1978). Single-dose tolerance to antinociception, and physical dependence on $\beta$-endorphin in mice. Eur J Pharmacol 52: 179-189.

Jensen TS, Yaksh TL (1986). III. Comparison of the antinociceptive action of $\mathrm{mu}$ and delta opioid receptor ligands in the periaqueductal grey matter, medial and paramedial ventral medulla in the rat as studied by the microinjection technique. Brain Res 372: 301-312.

Kest B, Lee CE, Mclemore GL, Inturrisi CE (1996). An antisense oligodeoxynucleotide to the $\delta$ opioid receptor (DOR-1) inhibits morphine tolerance and acute dependence in mice. Brain Res Bull 39: 185-188.

Kim E, Arnould T, Sellin L, Benzing T, Comella N, Kocher O et al (1999). Interaction between RGS7 and polycystin. Proc Natl Acad Sci USA 96: 6371-6376. 
Levac BA, O'Dowd BF, George SR (2002). Oligomerization of opioid receptors: generation of novel signaling units. Curr Opin Pharmacol 2: 76-81.

Munson PJ, Rodbard D (1980). LIGAND: a versatile computerized approach for characterization of ligand-binding systems. Anal Biochem 107: 220-239.

Miyamoto Y, Portoghese PS, Takemori AE (1993). Involvement of $\delta 2$ opioid receptors in the development of morphine dependence in mice. J Pharmacol Exp Ther 264: 1141-1145.

Ni YG, Gold SJ, Iredale PA, Terwilliger RZ, Duman RS, Nestler EJ (1999). Region-specific regulation of RGS4 (regulator of Gprotein-signaling protein type 4) in brain by stress and glucocorticoids: in vivo and in vitro studies. J Neurosci 19: 3674-3680.

Nitsche JF, Schuller AGP, King MA, Zengh M, Pasternak GW, Pintar JE (2002). Genetic dissociation of opiate tolerance and physical dependence in $\delta$-opioid receptor-1 and preproenkephalin knock-out mice. J Neurosci 22: 10906-10913.

Posner BA, Gilman AG, Harris BA (1999). Regulators of G protein signaling 6 and 7. Purification of complexes with $G \beta 5$ and assessment of their effects on $G$ protein-mediated signaling pathways. J Biol Chem 274: 31087-31093.

Rahman Z, Gold SJ, Potenza MN, Cowan CW, Ni YG, He W et al (1999). Cloning and characterization of RGS9-2: a striatalenriched alternatively spliced product of the RGS9 gene. J Neurosci 19: 2016-2026.

Rose JJ, Taylor JB, Cockett MI, Jones PG, Hepler JR (2000). RGS7 is palmitoylated and exists as biochemically distinct forms. $J$ Neurochem 75: 2103-2112.

Ross EM, Wilkie TM (2000). GTPase-activating proteins for heterotrimeric $\mathrm{G}$ proteins: regulators of $\mathrm{G}$ protein signaling (RGS) and RGS-like proteins. Ann Rev Biochem 69: 795-827.

Rossi GC, Pasternak GW, Bodnar RJ (1994). $\mu$ and $\delta$ opioid synergy between the periaqueductal gray and the rostroventral medulla. Brain Res 665: 85-93.

Saitoh O, Kubo Y, Odagiri M, Ichikawa M, Yamagata K, Sekine T (1999). RGS7 and RGS8 differentially accelerate G proteinmediated modulation of $\mathrm{K}^{+}$currents. $J$ Biol Chem 14: 9899-9904.

Sánchez-Blázquez P, García-España A, Garzón J (1995). In vivo injection of oligodeoxynucleotides to $\mathrm{G} \alpha$ subunits and supraspinal analgesia evoked by $\mathrm{mu}$ and delta opioid agonists. $J$ Pharmacol Exp Ther 275: 1590-1596.

Sánchez-Blázquez P, García-España A, Garzón J (1997). Antisense oligodeoxynucleotides to opioid $\mathrm{Mu}$ and Delta receptors reduced morphine dependence in mice: role of Delta-2 opioid receptors. $J$ Pharmacol Exp Ther 280: 1423-1431.

Sánchez-Blázquez P, Garzón J (1993). Opioid supraspinal antinociception in mice is mediated by Gi3 transducer proteins. Life Sci/Pharmacol Lett 53: PL129-PL134.
Sánchez-Blázquez P, Garzón J (1998). Delta opioid receptor subtypes activate inositol-signaling pathways in the production of antinociception. J Pharmacol Exp Ther 285: 820-827.

Sánchez-Blázquez $\mathrm{P}$, Juarros JL, Martínez-Peña Y, Castro MA, Garzón J (1993). Gx/z and Gi2 transducer proteins on $\mu / \delta$ opioid-mediated supraspinal antinociception. Life Sci/Pharmacol Lett 53: PL381-PL386.

Sánchez-Blázquez P, Rodríguez-Díaz M, López-Fando A, Rodríguez-Muñoz M, Garzón J (2003). The GBeta5 subunit that associates with the R7 subfamily of RGS proteins regulates muopioid effects. Neuropharmacology 45: 82-95.

Sierra DA, Popov S, Wilkie TM (2000). Regulators of G-protein signaling in receptor complexes. Trends Cardiovas Med 10: 263-228.

Snow BE, Krumins AM, Brothers GM, Lee S-F, Wall MA, Chung S et al (1998). A G protein $\gamma$ subunit-like domain shared between RGS11 and other RGS proteins specifies binding to G $\beta 5$ subunits. Proc Natl Acad Sci USA 95: 13307-13312.

Sondek J, Siderovski DP (2001). G $\gamma$-like (GGL) domains: new frontiers in G-protein signaling and beta-propeller scaffolding. Biochem Pharmacol 61: 1329-1337.

Standifer KM, Rossi GC, Pasternak GW (1996). Differential blockade of opioid analgesia by antisense oligodeoxynucleotides directed against various $\mathrm{G}$ protein $\alpha$ subunits. Mol Pharmacol 50: 293-298.

Thomas EA, Danielson PE, Sutcliffe JG (1998). RGS9: a regulator of G-protein signalling with specific expression in rat and mouse striatum. J Neurosci Res 52: 118-124.

Watson AJ, Aragay AM, Slepak VZ, Simon MI (1996). A novel form of the $\mathrm{G}$ protein $\beta$ subunit $\mathrm{G} \beta 5$ is specifically expressed in the vertebrate retina. J Biol Chem 271: 28154-28160.

Watson AJ, Katz A, Simon MI (1994). A fifth member of the mammalian G-protein $\beta$-subunit family. $J$ Biol Chem 269: 22150-22156.

Yaksh TL, Yeung JC, Rudy TA (1976). Systematic examination in the rat of brain sites sensitive to the direct application of morphine: observation of differential effects within the periaqueductal grey. Brain Res 114: 83-103.

Zhang J-H, Lai Z, Simonds WF (2000). Differential expression of the $\mathrm{G}$ protein $\beta 5$ gene: analysis of mouse brain, peripheral tissues, and cultured cell lines. J Neurochem 75: 393-403.

Zhang JH, Simonds WF (2000). Copurification of brain G-protein $\beta 5$ with RGS6 and RGS7. J Neurosci 20, RC59 (1-5).

Zheng B, Ma YC, Ostrom RS, Lavoie C, Gill GN, Insel GN et al (2001). RGS-PX1, a GAP for G $\alpha$ s and sorting nexin in vesicular trafficking. Science 30: 1939-1942.

Zhu Y, King MA, Schuller AGP, Nitsche JF, Reidi M, Elde RP et al (1999). Retention of supraspinal delta-like analgesia and loss of morphine tolerance in $\delta$ opioid receptor kockout mice. Neuron 24: $243-252$. 